\title{
PCR-based assays for the fish pathogen Aeromonas salmonicida. II. Further evaluation and validation of three PCR primer sets with infected fish
}

\author{
Helen K. Byers ${ }^{1}$, Rocco C. Cipriano ${ }^{2}$, Nicholas Gudkovs ${ }^{1}$, Mark St. J. Crane ${ }^{1, *}$ \\ ${ }^{1}$ Australian Animal Health Laboratory, CSIRO Livestock Industries, Private Bag 24, Geelong VIC 3220 Australia \\ ${ }^{2}$ National Fish Health Research Laboratory, United States Geological Survey, Biological Resources Division, \\ 1700 Leetown Road, Kearneysville, West Virginia 25430, USA
}

\begin{abstract}
Two Aeromonas salmonicida-specific polymerase chain reaction (PCR) tests and $1 \mathrm{~A}$. salmonicida subsp. salmonicida-specific PCR test were used to screen salmonid populations that were either overtly or covertly infected with $A$. salmonicida subsp. salmonicida. It was demonstrated that these PCR assays could be used to replace the biochemical testing currently employed to confirm the identity of A. salmonicida isolates cultured from infected fish. The AP and PAAS PCR assays were also capable of direct detection of $A$. salmonicida in overtly infected fish, with mucus, gill and kidney samples most likely to yield a positive result. Culture was a more reliable method for the direct detection of A. salmonicida in covertly infected salmonids than was the direct PCR testing of tissue samples, with the AP and PAAS PCRs having a lower detection limit (LDL) of approximately $4 \times 10^{5}$ colony-forming units (CFU) $\mathrm{g}^{-1}$ sample.
\end{abstract}

KEY WORDS: Aeromonas salmonicida - Polymerase chain reaction - Detection - Identification · Validation $\cdot$ Naturally infected fish $\cdot$ Covert infections

\section{INTRODUCTION}

The bacterial pathogen Aeromonas salmonicida is responsible for a range of clinical syndromes in a wide variety of fish species, including furunculosis of salmonids caused by $A$. salmonicida subsp. salmonicida (also referred to as typical $A$. salmonicida), which is exotic to Australia (DPIE 1996). The threat that this disease poses to the Australian salmonid industry is compounded by the fact that the bacterium can be present in a clinically inapparent or 'covert' state of infection that is very difficult to detect. Infections may remain covert or they may become overt, depending upon environmental conditions such as trauma and poor water quality that stress carrier hosts (Hiney et al. 1997). Thus, covertly infected fish play a significant role in the epizootiology of the disease. The extensive

${ }^{*}$ Corresponding author. E-mail: mark.crane@csiro.au range of known carriers of A. salmonicida (Hiney \& Olivier 1999) increases the opportunities for transmission of the microorganism to susceptible fish. Furthermore, because there are no restrictions on access to sea-cage sites, feral populations of fish are attracted by the abundance of food. Consequently, covertly infected populations used in mariculture could act as an additional source of contagion among feral fish.

The current standard method for detecting carriers is culture from kidney and spleen of fish subjected to the stress-induced furunculosis (SIF) assay (Bullock \& Stuckey 1975, McCarthy 1977). This process is resource intensive, time consuming and expensive. Polymerase chain reaction (PCR) assays are being developed for the detection and identification of Aeromonas salmonicida, and this technology may offer an alternative means of detecting latent infections. Such an approach could address the most significant problems associated with either the detection of covert 
infections or identification of atypical isolates of $A$. salmonicida that are difficult to classify phenotypically. It is important to note that the application of nonculture-based, 'proxy' methods such as PCR, enzymelinked immunosorbent assay (ELISA) and western blotting require extensive validation (Hiney 1997). The PCR assays used in this study have been evaluated previously (Byers et al. 2002 in this issue) at the in vitro level, the 'sterile seeded microcosm' level and the 'non-sterile incurred microcosm' stage in accordance with the framework proposed by Hiney \& Smith (1998). The final stage of validation depends on field trials. In this study, salmonid populations in the USA, which were infected with $A$. salmonicida subsp. salmonicida, were examined. The PCR assays were used to screen these populations for the presence of A. salmonicida, and the performance of these assays was compared to that of culture and biochemical testing for the detection and identification of A. salmonicida.

\section{MATERIALS AND METHODS}

Overt infection in Arctic char by bath exposure. Experiments involving overt infection in Arctic char Salvelinus alpinus with Aeromonas salmonicida subsp. salmonicida were conducted at the National Fish Health Research Laboratory (NFHRL; Kearneysville, West Virginia, USA). Labrador and Nauyuk strains of Arctic char $(\mathrm{n}=18)$ were placed in water containing $10^{5}$ colony-forming units (CFU) of A. salmonicida $\mathrm{ml}^{-1}$ for $30 \mathrm{~min}$. Fish were then transferred to $50 \mathrm{l}$ aquaria, maintained at approximately $12.5^{\circ} \mathrm{C}$ and monitored daily for clinical signs of disease, including the development of lesions, lethargy, colour change and other abnormal behaviour. Fish that displayed any signs of disease were euthanised using benzocaine at $100 \mathrm{mg}$ $\mathrm{l}^{-1}$. Unexposed control fish $(\mathrm{n}=10)$ were maintained in a separate tank and sampled at the end of the experiment.

Overt infection in rainbow trout and Atlantic salmon induced by stress. Experiments to induce overt infection in rainbow trout Oncorhynchus mykiss and Atlantic salmon Salmo salar with Aeromonas salmonicida subsp. salmonicida were also conducted at NFHRL. Some of the Atlantic salmon used had been vaccinated (against A. salmonicida subsp. salmonicida) on an annual basis (in May) with the Aquavet oil emulsion vaccine. Thus, the fish used in these experiments had received a vaccine dose approximately $1 \mathrm{yr}$ prior to sampling. Rainbow trout $(\mathrm{n}=20)$, unvaccinated Atlantic salmon $(\mathrm{n}=20)$ and vaccinated Atlantic salmon ( $\mathrm{n}=24)$ suspected to be covertly infected with A. salmonicida were subjected to the SIF assay. This assay was conducted as described by McCarthy (1977) except that fish were injected intraperitoneally with $0.1 \mathrm{ml}$ prednisolone 21-hemisuccinate (Sigma) rather than prednisolone 21 -acetate, at a rate of $20 \mathrm{mg} \mathrm{kg}^{-1}$ fish. The fish were held at $18^{\circ} \mathrm{C}$. Aquaria were checked daily and dead fish were removed for processing as described below. On Day 8 post-administration of the steroid, any remaining rainbow trout were euthanised, and on Day 9 post-administration, any remaining Atlantic salmon were euthanised and processed for detection of $A$. salmonicida.

Cultural identification and quantification of bacterial flora from fish. Bacteria were isolated from the infected fish tissues (gill, spleen, kidney and intestine) and mucus, and were identified according to the method of Cipriano et al. (1992).

Detection of Aeromonas salmonicida in tissue samples collected from covertly infected salmonids. $A$. salmonicida subsp. salmonicida had previously been isolated from Atlantic salmon that had survived epizootics of furunculosis in raceways at the Richard Cronin National Salmon Station (RCNSS; Sunderland, Massachusetts, USA) and, therefore, this population was believed to be covertly infected (Cipriano et al. 1996e). These fish were age $3+$ reconditioned kelts and were held at the hatchery for the ongoing New England Salmon Restoration Program. Because these fish could not be sacrificed for sampling, detection of $A$. salmonicida was attempted only from mucus samples of individual salmon $(\mathrm{n}=100)$.

Mucus, gill, spleen, kidney and intestine samples were also collected from the following:

(1) Experimental Atlantic salmon ( $\mathrm{n}=40)$ also maintained at the same facility. These Atlantic salmon were age 2+ excess domestic stock and were receiving runoff water from the covertly infected re-conditioned kelts, described previously. Ongoing mortality was reported in this population and Aeromonas salmonicida was isolated from dead fish.

(2) Age $1+$ brown trout $(n=20)$ located at a Vermont Fish and Wildlife fish culture station (Bennington, Vermont, USA). Ongoing mortality had been reported in this population and Aeromonas salmonicida had previously been isolated from these fish.

(3) Rainbow trout $(n=20)$ and unvaccinated Atlantic salmon $(\mathrm{n}=20)$ held at NFHRL. These fish were covertly infected with Aeromonas salmonicida as indicated by results of SIF assays that were conducted on a proportion of each population.

Whenever lethal samples were obtained, individual fish were euthanised in tricaine methane sulphonate (MS-222, Argent Chemical Laboratories). The tissue samples were divided into 2 equal aliquots: one portion was used for direct PCR tests, and the other portion was used for quantitative culture of Aeromonas salmonicida. 
PCR identification of Aeromonas salmonicida from fish tissue. Mucus, gill, intestine, kidney and spleen samples were taken from the overtly infected (diseased) fish. DNA was extracted and amplified by PCR as described previously (Byers et al. 2002).

\section{RESULTS}

\section{Generation of overt infection in salmonids}

Overt infection was generated in Arctic char via a bath challenge and, in covertly infected rainbow trout and Atlantic salmon (both vaccinated and unvaccinated), via SIF assays.

\section{Culture-based identification of Aeromonas salmonicida in overtly infected fish tissues}

Both mixed bacterial cultures and pure cultures of Aeromonas salmonicida subsp. salmonicida (as identified by the biochemical tests employed by NFHRL) were isolated on Coomassie Brilliant Blue (CBB) agar from tissues of necropsied fish. Identification of suspected A. salmonicida isolates based on the AP and PAAS combined PCR tests, and of suspected A. salmonicida subsp. salmonicida isolates based on the MIY PCR test agreed with the biochemical test results in all cases. PCR of pure cultures was faster than phenotypic screening. Typically PCR tests yielded results in 1 to $2 \mathrm{~d}$, compared to $4 \mathrm{~d}$ for classical biochemical testing.

\section{Direct PCR detection of Aeromonas salmonicida in overtly infected fish tissues}

All dead fish obtained prior to Day 8 post-administration of the SIF assay were PCR positive for all samples collected, without the need for an enrichment culture phase prior to PCR. Of the surviving fish that were euthanised after Day 8, 1 vaccinated Atlantic salmon and 3 rainbow trout were PCR negative for all tissue samples. Overall, at least 1 sample was PAAS and AP PCR positive for $95 \%$ of all fish tested (Table 1).

Mucus was the sample most likely, while intestine was least likely, to yield a PCR-positive result (Table 1). No sample that was positive for Aeromonas salmonicida by PCR screening was negative for A. salmonicida by culture on CBB agar. Presence of A. salmonicida subsp. salmonicida as determined by PCR correlated with positive results based on the biochemical testing of isolates of mucus and kidney samples taken from the rainbow trout.

\section{Quantification of bacterial flora from covertly infected fish}

A variety of bacteria, including Aeromonas salmonicida, were isolated from the 100 mucus samples taken from the age 3+ Atlantic salmon kelts sampled nonlethally at RCNSS. These bacteria were subsequently identified using biochemical tests (data not shown). A. salmonicida was not isolated among the experimental age 2+ domestic Atlantic salmon held at the RCNSS, nor from the brown trout located at Bennington. The pathogen was isolated from the rainbow trout and the unvaccinated Atlantic salmon located at NFHRL.

The levels of Aeromonas salmonicida determined to be present in the samples ranged from $8.3 \times 10^{2}$ to $2 \times$ $10^{6} \mathrm{CFU} \mathrm{g}^{-1}$ (Table 2). The number and type of $A$. salmonicida culture-positive samples found in the lethally sampled fish $(\mathrm{n}=40$ ) were 8 mucus, 9 gill, 3 kidney, 2 spleen and 2 intestine (Table 2). Six fish were culture positive by gill samples only, and 4 fish were culture positive by mucus samples only. No fish was culture positive based solely on kidney, spleen or intestine samples. As shown previously with overt infections, results from the AP and PAAS combined PCR tests and the MIY PCR test agreed with the biochemical tests currently employed by NFHRL to identify A. salmonicida and A. salmonicida subsp. salmonicida (Table 2).

The PCR assays were tested on a variety of the normal bacterial flora isolated from these samples, including Pseudomonas diminuta, P. pseudoalcaligenes, $P$. fluorescens, Aeromonas hydrophila, Commomonas tarrigania, Shewanella putrefasciens, Acinetobacter sp., Staphylococcus sp. and Moraxella sp. No false positive reactions occurred, further demonstrating the specificity of the PCR tests for Aeromonas salmonicida.
Table 1. Proportion of samples from overtly infected salmonids demonstrated, by direct PCR, to be infected with Aeromonas salmonicida

\begin{tabular}{|lcccc|}
\hline \multirow{2}{*}{ Tissue } & \multicolumn{4}{c}{ Salmonid test group } \\
\cline { 2 - 5 } & Arctic char & $\begin{array}{c}\text { Rainbow } \\
\text { trout }\end{array}$ & $\begin{array}{c}\text { Atlantic } \\
\text { salmon } \\
\text { (vaccinated) }\end{array}$ & $\begin{array}{c}\text { Atlantic } \\
\text { salmon } \\
\text { (unvaccinated) }\end{array}$ \\
\hline Mucus & $18 / 18(100 \%)$ & $16 / 20(80 \%)$ & $18 / 24(75 \%)$ & $16 / 16(100 \%)$ \\
Gill & $6 / 18(33 \%)$ & $12 / 20(60 \%)$ & $17 / 24(71 \%)$ & $16 / 16(100 \%)$ \\
Spleen & $5 / 18(28 \%)$ & $7 / 20(35 \%)$ & $18 / 24(75 \%)$ & $16 / 16(100 \%)$ \\
Kidney & $8 / 18(44 \%)$ & $8 / 20(40 \%)$ & $19 / 24(79 \%)$ & $16 / 16(100 \%)$ \\
Intestine & $2 / 18(11 \%)$ & $7 / 20(35 \%)$ & $17 / 24(71 \%)$ & $16 / 16(100 \%)$ \\
\hline
\end{tabular}


Table 2. Comparison of PCR testing of Aeromonas salmonicida isolates and samples of covertly infected fish. CFU: colonyforming units; NFHRL: National Fish Health Research Laboratory; RCNSS: Richard Cronin National Salmon Station. +: positive; -: negative; $(+)$ : extremely weak positive reaction

\begin{tabular}{|c|c|c|c|c|c|c|c|c|c|c|}
\hline \multirow[t]{2}{*}{ Salmonid species } & \multirow[t]{2}{*}{ Location } & \multirow[t]{2}{*}{ Fish no. } & \multirow[t]{2}{*}{ Sample } & \multirow{2}{*}{$\begin{array}{l}\text { A. salmonicida } \\
\text { CFU g }\end{array}$} & \multicolumn{3}{|c|}{ PCR of isolates } & \multicolumn{3}{|c|}{ PCR of tissues } \\
\hline & & & & & AP & PAAS & MIY & $\mathrm{AP}$ & PAAS & MIY \\
\hline \multirow[t]{8}{*}{$\begin{array}{l}\text { Atlantic salmon 3+ } \\
\text { kelts }\end{array}$} & RCNSS & 18 & Mucus & $2.0 \mathrm{E}+03$ & + & + & + & - & - & - \\
\hline & & 23 & Mucus & $7.7 \mathrm{E}+03$ & + & + & + & _- & _- & _- \\
\hline & & 56 & Mucus & $8.3 \mathrm{E}+02$ & + & + & + & - & - & - \\
\hline & & 63 & Mucus & $5.0 \mathrm{E}+03$ & + & + & + & _- & _- & - \\
\hline & & 66 & Mucus & $1.1 \mathrm{E}+03$ & + & + & + & - & - & - \\
\hline & & 78 & Mucus & $1.0 \mathrm{E}+03$ & + & + & + & _- & _- & - \\
\hline & & 97 & Mucus & $2.5 \mathrm{E}+03$ & + & + & + & - & - & - \\
\hline & & 100 & Mucus & $1.4 \mathrm{E}+04$ & + & + & + & - & - & - \\
\hline \multirow[t]{11}{*}{ Rainbow trout } & NFHRL & 5 & Mucus & $1.3 E+04$ & + & + & + & - & - & - \\
\hline & & & Gill & $6.7 \mathrm{E}+04$ & + & + & + & - & - & - \\
\hline & & & Spleen & $1.7 \mathrm{E}+05$ & + & + & + & - & - & - \\
\hline & & & Kidney & $4.0 \mathrm{E}+05$ & + & + & + & + & + & - \\
\hline & & & Intestine & $3.9 E+04$ & + & + & + & - & - & - \\
\hline & & 18 & Spleen & $2.0 \mathrm{E}+06$ & + & + & + & + & + & $(+)$ \\
\hline & & & Kidney & $1.9 E+05$ & + & + & + & - & - & - \\
\hline & & & Intestine & $1.8 \mathrm{E}+05$ & + & + & + & - & - & - \\
\hline & & 19 & Mucus & $1.3 E+05$ & + & + & + & + & + & $(+)$ \\
\hline & & & Gill & $1.3 \mathrm{E}+04$ & + & + & + & - & - & - \\
\hline & & 20 & Mucus & $1.9 \mathrm{E}+04$ & + & + & + & - & - & - \\
\hline \multirow{13}{*}{$\begin{array}{l}\text { Atlantic salmon } \\
\text { (unvaccinated) }\end{array}$} & NFHRL & 1 & Gill & $2.0 \mathrm{E}+03$ & + & + & + & - & - & - \\
\hline & & 2 & Mucus & $7.1 \mathrm{E}+04$ & + & + & + & - & - & - \\
\hline & & 5 & Mucus & $5.0 \mathrm{E}+04$ & + & + & + & - & - & - \\
\hline & & & Kidney & $6.3 \mathrm{E}+03$ & + & + & + & - & - & - \\
\hline & & 7 & Mucus & $2.0 \mathrm{E}+05$ & + & + & + & - & + & - \\
\hline & & 9 & Gill & $2.9 \mathrm{E}+04$ & + & + & + & - & - & - \\
\hline & & 11 & Gill & $5.0 \mathrm{E}+04$ & + & + & + & - & - & - \\
\hline & & 15 & Gill & $2.5 \mathrm{E}+04$ & + & + & + & - & - & - \\
\hline & & 17 & Gill & $1.0 \mathrm{E}+05$ & + & + & + & + & + & - \\
\hline & & 18 & Gill & $1.0 \mathrm{E}+04$ & + & + & + & - & - & - \\
\hline & & 19 & Mucus & $2.9 E+05$ & + & + & + & + & + & - \\
\hline & & 20 & Mucus & $2.3 \mathrm{E}+04$ & + & + & + & - & - & - \\
\hline & & & Gill & $6.0 \mathrm{E}+04$ & + & + & + & - & - & - \\
\hline
\end{tabular}

\section{Direct PCR detection of Aeromonas salmonicida from covertly infected fish tissue}

All samples taken from the age 2+ Atlantic salmon domestic stock at RCNSS and the brown trout from Bennington were negative for Aeromonas salmonicida by culture and by direct PCR screening.

Results from the direct PCR screening of samples taken from fish that were positive for Aeromonas sal-

Table 3. Comparison of cultural isolation of Aeromonas salmonicida vs direct PCR detection of $A$. salmonicida in tissues from covertly infected salmonids

\begin{tabular}{|lcc|}
\hline $\begin{array}{l}\text { Source of covertly } \\
\text { infected tissue }\end{array}$ & $\begin{array}{l}\text { Positive by } \\
\text { culture (\%) }\end{array}$ & $\begin{array}{c}\text { Positive by } \\
\text { direct PCR (\%) }\end{array}$ \\
\hline $\begin{array}{l}\text { Atlantic salmon, 3+ kelts, } \\
\text { RCNSS (n = 100) }\end{array}$ & 8 & 0 \\
$\begin{array}{l}\text { Rainbow trout, } \\
\text { NFHRL ( }=20)\end{array}$ & 20 & 15 \\
$\begin{array}{l}\text { Atlantic salmon (unvaccinated), } \\
\text { NFHRL (n = 20) }\end{array}$ & 55 & 15 \\
\hline
\end{tabular}

monicida by culture are given in Table 2 . No tissue sample that was positive for $A$. salmonicida by PCR screening was negative for $A$. salmonicida by culture. These results show that culture was more reliable than direct PCR for detection of A. salmonicida in covertly infected fish (Table 3).

\section{DISCUSSION}

The SIF assay was used to generate overt infection in rainbow trout and Atlantic salmon held at NFHRL, thereby confirming that these populations were covertly infected. In addition, bath challenge with Aeromonas salmonicida generated overt, albeit experimental, infection in Arctic char. Bacteria isolated from these overtly infected fish populations were successfully identified as A. salmonicida using the AP and PAAS PCRs, and as A. salmonicida subsp. salmonicida using the MIY PCR. All PCR results were in agreement with the biochemical tests currently employed by NFHRL to identify A. salmonicida and A. salmonicida subsp. salmonicida. 
The AP and PAAS PCRs were also used to detect Aeromonas salmonicida in tissue and mucus samples taken from the overtly diseased fish. Cipriano et al. (1992, 1994b, 1996a,c,d) have previously reported levels of $A$. salmonicida in overtly infected fish, including Atlantic salmon, ranging from $10^{3}$ to $10^{7} \mathrm{CFU} \mathrm{g}^{-1}$, and even as high as $10^{9} \mathrm{CFU} \mathrm{g}^{-1}$, in both kidney and mucus samples. Given that the detection limits of the PCRs cover at least part of this range (Byers et al. 2000), it was not surprising to find that direct PCR detection of overtly infected tissues was possible in many instances. The fact that mucus yielded PCR products more often than tissues, especially intestine, may indicate that the pathogen occurs in higher numbers in some locations than in others or that some types of infected tissues may inhibit the PCR more than others.

Aeromonas salmonicida was detected by culture in covertly infected salmonid populations, e.g. the Atlantic salmon kelts at RCNSS, and rainbow trout and Atlantic salmon populations held at NFHRL. The pathogen load ranged between $8.3 \times 10^{2}$ and $2 \times 10^{6} \mathrm{CFU} \mathrm{g}^{-1}$ sample. These levels are higher than those reported by Nomura et al. (1993) of $10^{2} \mathrm{CFU} \mathrm{g}^{-1}$ in pink salmon Oncorhynchus gorbuscha and $10^{1} \mathrm{CFU} \mathrm{g}^{-1}$ kidney in chum salmon $O$. keta, but are within the range reported by other researchers, as cited by Hiney et al. (1997).

Aeromonas salmonicida was cultured predominantly from the gill and mucus samples of covertly infected fish. Only 3 of the 15 culture-positive, lethally sampled salmonids $(\mathrm{n}=40)$ had systemic infections, i.e. kidney, spleen or both were culture positive. However, 2 of these systemically infected fish were not culture positive using either gill or mucus samples, demonstrating the importance of sampling more than 1 host site when attempting to detect $A$. salmonicida from covertly infected fish (Cipriano et al. 1996b, Bernoth 1997). The predominance of the external surfaces of the fish as the site of pathogen carriage is also consistent with the findings of Cipriano et al. (1994a, 1996a,b). The PCR assays correctly determined the identity of the A. salmonicida isolates in a shorter time than that required by conventional biochemical testing, again demonstrating their usefulness with regard to confirming the identity of colonies presumptively identified as $A$. salmonicida by characteristic growth on CBB agar.

PCR tests detected Aeromonas salmonicida in the covertly infected rainbow trout and Atlantic salmon populations held at NFHRL, but culture methods were more reliable. The PCR assays completely failed to yield positive results for the age 2+ Atlantic salmon held at RCNSS, which was most likely due to pathogen concentrations below the detection limits of these tests. Our results indicated that, for covertly infected tissues, the level of detection for the AP and PAAS PCRs was approximately $4 \times 10^{5} \mathrm{CFU} \mathrm{g}^{-1}$ sample. Although there were instances where the PCRs detected lower numbers than this, detection at lower levels was inconsistent. In no instance was a sample PCR positive but culture negative, and thus false positive results with these PCR assays were not encountered during this survey. In addition, no particular tissue sample site was consistently PCR negative, suggesting that the main constraint on direct detection was the lower detection limit (LDL) of the respective PCR assays. It is interesting to note that the LDL of the PCRs does not equate to those levels determined previously by the seeded tissue studies (Byers et al. 2000). This observation highlights the danger of inferring the performance of an assay from laboratory studies alone.

The failure to detect Aeromonas salmonicida by either culture or PCR in the age 2+ experimental Atlantic salmon held at RCNSS or the brown trout from Bennington could be due to a number of factors. Firstly, as the LDL of culture is estimated to be around $10^{2} \mathrm{CFU} \mathrm{g}^{-1}$ sample (Cipriano 1997), the occurrence of the target pathogen at levels lower than this would produce false negative results. Secondly, only singlepoint inspections were performed on these populations, and it has been noted that such inspections can produce erroneous results (Cipriano et al. 1994a), possibly as a result of the proposed transient nature of covert infections (Scallan et al. 1993). It has also been found that sampling at multiple points over time can provide greater accuracy in the cultural detection of $A$. salmonicida in covertly infected salmonids (Cipriano et al. 1997). Unfortunately, it was not possible to incorporate such a sampling regimen in this study. These issues may have been resolved by use of the SIF assay, which has been reported to be more reliable than culture and to provide the most definitive single-point assay for the detection of covert A. salmonicida infections (Cipriano et al. 1997). However, it was not possible to conduct the SIF assay on these salmonid populations because of the lack of appropriate facilities at RCNSS. Thirdly, the prevalence of the pathogen may have been at such low levels that a larger sample size was required.

Hiney \& Smith (1998) in their discussion on the validation of proxy methods state that the 'major role [of validation] is in providing rational grounds for rejecting techniques whose application to environmentally derived matrices has been shown to be invalid.' Since the primary aim of this study was to use PCR to establish the presence or absence of Aeromonas salmonicida, as opposed to predicting the consequences of the presence of the pathogen, it was pertinent to use the principle of comparative validation (Hiney \& Smith 1998), i.e. the performance of the PCRs was compared to previously validated, standard techniques. 
This study demonstrated that PCR technology can be used to replace the biochemical testing currently used to confirm the identity of Aeromonas salmonicida isolates cultured from both overtly and covertly infected salmonids. The AP and PAAS PCR assays were also capable of direct detection of A. salmonicida in overtly infected fish, with mucus, gill and kidney samples most likely to yield a positive result. Culture, however, was a more reliable and sensitive method for the detection of A. salmonicida in covertly infected salmonids than direct PCR testing of tissue samples. It is highly recommended, therefore, that any target pathogen that may be present in the tissues of covertly infected fish be first concentrated by a culture step, as used in this study, prior to PCR. Still, it is important to note that culture alone did not detect $A$. salmonicida in all salmonid populations either, but the development of a medium selective for A. salmonicida, and the use of multiplepoint sampling regimens, could possibly alleviate some of the problems associated with the detection of this pathogen among covertly infected fish.

Acknowledgements. The authors acknowledge support from the Fisheries Research and Development Corporation Project \#95/060.

\section{LITERATURE CITED}

Bernoth EM (1997) Diagnosis of furunculosis: the tools. In: Bernoth EM, Ellis AE, Midtlyng PJ, Olivier G, Smith P (eds) Furunculosis: multidisciplinary fish disease research. Academic Press, London, p 98-158

Bullock GL, Stuckey HM (1975) Aeromonas salmonicida: detection of asymptomatically infected trout. Prog Fish-Cult 37:237-239

Byers HK, Gudkovs N, Crane MS (2000) Diagnosis and identification of Aeromonas salmonicida and detection of latent infections in carrier fish: final report on FRDC project 95/060. CSIRO Australian Animal Health Laboratory, Geelong

Byers HK, Gudkovs N, Crane MS (2002) PCR-based assays for the fish pathogen Aeromonas salmonicida. I. Evaluation of 3 PCR primer sets for detection and identification. Dis Aquat Org 49:129-138

Cipriano RC (1997) Strategies for management of furunculosis in Atlantic salmon effected by non-lethal detection of Aeromonas salmonicida: a review. Bull Eur Assoc Fish Pathol 17:215-219

Cipriano RC, Ford LA, Teska JD, Hale LE (1992) Detection of Aeromonas salmonicida in the mucus of salmonid fishes. $\mathrm{J}$ Aquat Anim Health 4:114-118

Cipriano RC, Ford LA, Jones TE (1994a) Relationship between resistance of salmonids to furunculosis and recovery of Aeromonas salmonicida from external mucus. J Wildl Dis 30:577-580

Editorial responsibility: Carey Cunningham, Aberdeen, Scotland, UK
Cipriano RC, Ford LA, Schachte JH, Petrie C (1994b) Evaluation of mucus as a valid site to isolate Aeromonas salmonicida among asymptomatic populations of lake trout (Salvelinus namaycush). Biomed Lett 49:229-233

Cipriano RC, Bullock GL, Noble A (1996a) Nature of Aeromonas salmonicida carriage on asymptomatic rainbow trout maintained in a culture system with recirculating water and fluidized sand biofilters. J Aquat Anim Health 8:47-51

Cipriano RC, Bullock GL, Schill WB, Kretschmann R (1996b) Enhanced culture of Aeromonas salmonicida from covertly infected rainbow trout following administration of the stress induced furunculosis test. Biomed Lett 54: $105-112$

Cipriano RC, Ford LA, Nelson JT, Jenson BN (1996c) Monitoring for early detection of Aeromonas salmonicida to enhance antibiotic therapy and control furunculosis in Atlantic salmon. Prog Fish-Cult 58:203-208

Cipriano RC, Ford LA, Starliper CE, Teska JD, Nelson JT, Jensen BN (1996d) Control of external Aeromonas salmonicida: topical disinfection of salmonids with Chloramine-T. J Aquat Anim Health 8:52-57

Cipriano RC, Ford LA, Teska JD, Schachte JH and 3 others (1996e) Use of non-lethal procedures to detect and monitor Aeromonas salmonicida in potentially endangered or threatened populations of migrating and post-spawning salmon. Dis Aquat Org 27:233-236

Cipriano RC, Ford LA, Smith DR, Schachte JH, Petrie CJ (1997) Differences in detection of Aeromonas salmonicida in covertly infected salmonid fishes by the stress-inducible furunculosis test and culture-based assays. J Aquat Anim Health 9:108-113

DPIE (Department of Primary Industry and Energy) (1996) Salmon import risk analysis. Australian Government Publishing Service, Canberra, p 134-144

Hiney M (1997) How to test a test: methods of field validation for nonculture-based detection techniques. Bull Eur Assoc Fish Pathol 17:245-250

Hiney M, Olivier G (1999) Furunculosis (Aeromonas salmonicida). In: Woo PTK, Bruno DW (eds) Fish diseases and disorders, Vol 3. Viral, bacterial and fungal infections. CABI Publishing, New York, p 341-425

Hiney MP, Smith PR (1998) Validation of polymerase chain reaction-based techniques for proxy detection of bacterial fish pathogens: framework, problems and possible solution for environmental applications. Aquaculture 162: 41-68

Hiney MP, Smith P, Bernoth EM (1997) Covert Aeromonas salmonicida infections. In: Bernoth EM, Ellis AE, Midtlyng PJ, Olivier G, Smith P (eds) Furunculosis: multidisciplinary fish disease research. Academic Press, London, p 54-97

McCarthy DH (1977) Some ecological aspects of the bacterial fish pathogen: Aeromonas salmonicida. Soc Appl Bact Symp Aquat Microbiol 6:299-324

Nomura T, Yoshimizu M, Kimura T (1993) An epidemiological study of furunculosis in salmon propagation in Japanese rivers. Fish Res 17:137-146

Scallan A, Hickey C, Smith P (1993) Evidence for the transient nature of stress inducible asymptomatic Aeromonas salmonicida infections of Atlantic salmon. Bull Eur Assoc Fish Pathol 13:210-212

Submitted: July 17, 2001; Accepted: October 19, 2001

Proofs received from author(s): April 26, 2002 